Патогенетическая роль автономной нервной системы в ремоделировании сердца при артериальной гипотензии у молодых женщин

\author{
Баев В. М., Агафонова Т.Ю. \\ ФГБОУ ВО Пермский государственный медицинский университет им. академика Е. А. Вагнера \\ Минздрава России. Пермь, Россия
}

\begin{abstract}
Цель. Изучение особенностей ремоделирования сердца в зависимости от состояния автономной нервной системы (АНC) у молодых женщин с идиопатической артериальной гипотензией (ИАГ).

Материал и методы. Выполнен сравнительный анализ параметров эхокардиографии у женщин с ИАГ в возрасте 18-25 лет с преобладанием симпатического $(n=150)$ и парасимпатического $(n=60)$ отделов АНС. Критерием ИАГ считали уровень систолического артериального давления $\leqslant 98$ мм рт.ст. Активность АНС оценивали по индексу I. Kérdö.

Результаты. Показано, для женщин с ИАГ при симпатикотонии характерно достоверное уменьшение структурных параметров сердца: размеров всех камер и отверстия аорты, снижение сократительной функции и замедление релаксации левого желудочка (ЛЖ). Наблюдали ускорение внутрисердечной гемодинамики: увеличение скоростей кровотока и градиентов давления на митральном, трикуспидальном клапанах и клапане легочной артерии, увеличение скоростей раннего и позднего диастолического наполнения ЛЖ. Изменения в ранней диастоле ЛЖ ассоциированы с повышением давления в левом предсердии. У женщин с ИАГ при парасимпатикотонии выявили рестриктивный тип диастолической дисфункции.
\end{abstract}

Заключение. Симпатикотония и парасимпатикотония у молодых женщин с ИАГ ассоциируются с различными вариантами ремоделирования сердца. Гипотрофия сердца, снижение сократительной функции и нарушение релаксации ЛЖ при гипотензии ассоциируются со слабой симпатической активностью на фоне парасимпатикотонии. Рестриктивный тип диастолической дисфункции при гипотензии ассоциируется с парасимпатикотонией и отсутствием признаков активации симпатического отдела АНС. Перспективным направлением коррекции дисфункции АНС, регрессии ИАГ и ремоделирования сердца является использование холинолитиков и реактиваторов антихолинэстеразы.

Ключевые слова: идиопатическая артериальная гипотензия, ремоделирование сердца, автономная нервная система.

Конфликт интересов: не заявлен.

Кардиоваскулярная терапия и профилактика. 2019;18(1):67-72

http://dx.doi.org/10.15829/1728-8800-2019-1-67-72

Поступила 25/05-2018

Принята к публикации 06/08-2018

\title{
Pathogenetic role of the autonomic nervous system in arterial hypotension cardiac remodeling in young women
}

Baev V. M., Agafonova T. Yu.

E. A. Wagner Perm State Medical University of the Ministry of Health. Perm, Russia

Aim. To study the features of cardiac remodeling on condition of the autonomic nervous system (ANS) in young women with idiopathic arterial hypotension (IAH).

Material and methods. A comparative analysis of the echocardiography data in women with IAH aged 18-25 years with a predominance of sympathetic $(n=150)$ and parasympathetic $(n=60)$ parts of the ANS was performed. The level of systolic blood pressure $\leqslant 98 \mathrm{~mm} \mathrm{Hg}$ worked as the criterion of IAH. The activity of the ANS was evaluated by the I. Kérdö index.

Results. It has been shown that women with IAH with sympathicotonia are characterized by a significant decrease in the structural parameters of the heart: the size of all chambers and the aortic ostium, contractile function decrease and a slower relaxation of the left ventricle (LV). Acceleration of intracardiac hemodynamics was observed: an increase in blood flow rates and pressure gradients on the mitral, tricuspid and pulmonary artery valves, an increase in the rates of early and late diastolic LV filling. Changes in early LV diastole are associated with an increase of pressure in the left atrium. We identified a restrictive type of diastolic dysfunction in women with parasympathicotonia.

Conclusion. Sympathicotonia and parasympathicotonia in young women with IAH are associated with different heart remodeling variants. Cardiac hypotrophy, decrease of contractile function and impaired LV relaxation during hypotension are associated with low sympathetic activity against the background of parasympathicotonia. The restrictive type of diastolic dysfunction during hypotension is associated with parasympathicotonia. Use of cholinolytics and anticholinesterase reactivators are the potential way of correction of ANS dysfunction, IAH regression and cardiac remodeling.

Key words: idiopathic arterial hypotension, cardiac remodeling, autonomic nervous system.

Conflicts of interest: nothing to declare. 
Baev V. M. ORCID: 0000-0001-9283-8094, Agafonova T. Yu. ORCID: 0000-0001-9935-0040.

АД - артериальное давление, АНС - автономная нервная система, АЦХ - ацетилхолина, ВИ - вегетативный индекс, ИАГ - идиопатическая артериальная гипотензия, ЛЖ - левый желудочек, ПАНС - парасимпатический отдел автономной нервной системы, САД - систолическое АД, САНС - симпатический отдел автономной нервной системы, чСС - частота сердечных сокращений, NO - оксид азота.

\section{Введение}

Изучение здоровья молодых женщин с идиопатической артериальной гипотензией (ИАГ) выявило признаки гипотрофии сердца и диастолической левожелудочковой дисфункции [1]. Учитывая важную роль вегетативной дисфункции в патогенезе артериальной гипотензии, была выдвинута гипотеза о вероятной зависимости структурно-функциональных изменений сердца от состояния автономной нервной системы (АНС). Всестороннее исследование такой взаимосвязи поможет решить вопрос об эффективной терапии артериальной гипотензии. Поэтому целью исследование было изучение особенностей ремоделирования сердца в зависимости от состояния АНС у молодых женщин с ИАГ.

\section{Материал и методы}

Тип исследования - одномоментный. Объект исследования - молодые женщины с ИАГ. Предмет исследования - структурно-функциональные параметры сердца и состояние АНС. Критерии включения: добровольцы женского пола в возрасте 18-35 лет с ИАГ. Критерием ИАГ считали уровень систолического артериального давления (САД) $\leqslant 98$ мм рт.ст. [2].

Критерии исключения: синдромы Марфана, ЭлерсаДанло, несовершенный остеогенез, онкологические заболевания, сахарный диабет, гипотиреоз, недостаточность коры надпочечников, ревматические болезни, анемии, врожденные заболевания сердца и сосудов, оперированные сердце и сосуды, наркомания, острые инфекционные заболевания, ожирение, беременность. Первичный врачебный осмотр и исключение симптоматических гипотензий проведены на базе поликлиники ПГМУ в период профилактического медицинского осмотра для допуска студентов к занятиям физкультурой. Добровольцы осмотрены терапевтом, неврологом, эндокринологом, гинекологом, хирургом, травматологом-ортопедом, офтальмологом. Выполнены лабораторно-инструментальные исследования: измерение артериального давления (АД), частоты сердечных сокращений (ЧСС), веса, роста, индекс массы тела, анализы крови и мочи, рентгенография органов грудной клетки, электрокардиография. Обследовано 210 женщин. В зависимости от преобладания симпатического или парасимпатического отделов АНС (САНС и ПАНС) у женщин с ИАГ, сформированы две группы: I - с преобладанием активности симпатического отдела $(\mathrm{n}=150), 71 \%$ включенных в исследование, и II - c преобладанием парасимпатического отдела ( $\mathrm{n}=60), 29 \%$ включенных в исследование. Характеристика групп представлена в таблице 1.

АД измеряли после 5-минутного отдыха двукратно на правом плече в положении сидя (предплечье на уровне сердца) с интервалом в 3 мин, регистрировался средний результат. Использовался автоматический осциллометрический тонометр A\&D UA-777 (AGD Company Ltd., Япония, 2012). Преобладание САНС или ПАНС в состоянии покоя определяли по вегетативному индексу (ВИ) Kérdö I. [3]. Положительные значения индекса, включая нулевые, трактовались как преобладание симпатического отдела АНС, отрицательные - парасимпатического отдела. Эхокардиографию выполняли в горизонтальном положении после 15-минутного отдыха с помощью ультразвукового сканера SonoScape S6 (SONO SCAPE Co., Ltd. Китай, 2015г). Этические вопросы: лица, допущенные к обследованию, дали письменное согласие; план и дизайн исследования одобрены этическим комитетом ПГМУ (протокол № 13 от 25.11.2015г).

Статистический анализ проводился с помощью программы "Statistica 6.1" (серийный номерAXXR912E53722FA, StatSoft-Russia, 2009). Распределение вариационных рядов

Таблица 1

Характеристика изучаемых групп

\begin{tabular}{llll}
\hline Параметры & \multicolumn{1}{l}{ Группа I, $\mathrm{n}=150$} & Группа II, $\mathrm{n}=60$ & \\
\cline { 2 - 4 } & & \multicolumn{1}{c}{ Медиана, $(25-75 \%)$} & 0,11 \\
\hline Возраст, лет & $19(18-20)$ & $19(18-24)$ & 0,005 \\
\hline Вес, кг & $52(48-56)$ & $56(52-60)$ & 0,75 \\
\hline Рост, см & $162(158-168)$ & $162(158-167)$ & 0,043 \\
\hline ИМТ & $19(18-21)$ & $20(19-22)$ & 0,98 \\
\hline САД, мм рт.ст. & $97(93-98)$ & $98(95-98)$ & 0,001 \\
\hline ДАД, мм рт.ст. & $64(60-70)$ & $68(64-72)$ & 0,001 \\
\hline ЧСС, в мин & $74(70-80)$ & $62(58-65)$ & 0,11 \\
\hline ВИ & $14(6-21)$ & $-7(-14--4)$ & \\
\hline
\end{tabular}

Примечание: $\mathrm{p}$ - достоверность различия, ИМТ - индекс массы тела, ДАД - диастолическое АД. 
Таблица 2

Результаты сравнительного анализа эхокардиографических параметров между женщинами группы I и группы II

\begin{tabular}{|c|c|c|c|}
\hline \multirow[t]{2}{*}{ Параметр } & Группа I, n=150 & Группа II, n=60 & \multirow[t]{2}{*}{$\mathrm{p}$} \\
\hline & \multicolumn{2}{|c|}{ Медиана, (25-75\%) } & \\
\hline КДР ПЖ, мм & $20,4(18,0-23,0)$ & $21,7(21,4-23,0)$ & 0,001 \\
\hline Ao, мм & $25,4(24,5-26,7)$ & $25,6(24,2-26,7)$ & 0,42 \\
\hline Раскрытие АК, мм & $17,5(17,5-17,6)$ & $18,4(18,4-18,6)$ & 0,001 \\
\hline ЛП, мм & $27,4(26,0-29,0)$ & $29,2(27,8-31,0)$ & 0,001 \\
\hline ПП, мм & $35,0(35,0-35,1)$ & $35,7(35,6-35,7)$ & 0,001 \\
\hline ТМЖПд, мм & $7,5(7,1-7,6)$ & $7,6(7,1-8,0)$ & 0,14 \\
\hline ТМЖПс, мм & $9,4(8,8-9,5)$ & $10,0(8,9-11,2)$ & 0,016 \\
\hline ТЗСЛЖД, мм & $7,0(6,6-7,5)$ & $6,8(6,1-7,2)$ & 0,061 \\
\hline ТЗСЛЖс, мм & $9,5(9,0-9,9)$ & $9,5(8,8-9,9)$ & 0,22 \\
\hline КДР ЛЖ, мм & $43,7(42,4-44,9)$ & $44,0(42,0-46,1)$ & 0,52 \\
\hline КСР ЛЖ, мм & $27,9(26,4-29,3)$ & $28,7(26,3-30,6)$ & 0,10 \\
\hline Vmax ПК, см/сек & $83,9(77,4-91,4)$ & $77,6(70,3-81,0)$ & 0,001 \\
\hline Pgmax ПК, мм рт.ст. & $2,6(2,4-2,7)$ & $2,4(1,9-2,6)$ & 0,034 \\
\hline Vmax MK, см/сек & $88,1(84,9-90,0)$ & $87,3(83,1-87,3)$ & 0,020 \\
\hline Pgmax MK, мм рт.ст. & $3,1(2,8-3,2)$ & $3,0(2,6-3,0)$ & 0,008 \\
\hline Vmax AK, см/сек & $114,5(107,6-121,0)$ & $113,3(105,0-116,3)$ & 0,15 \\
\hline Pg max AK, мм рт.ст. & $5,3(4,6-5,7)$ & $5,4(4,4-5,5)$ & 0,83 \\
\hline Vmax TpK, см/сек & $55,0(53,7-60,7)$ & $59,4(56,8-63,0)$ & 0,004 \\
\hline Pg max TрК, мм рт.ст. & $1,3(1,1-1,5)$ & $1,3(1,2-1,5)$ & 0,73 \\
\hline $\mathrm{Ve},(\mathrm{cm} /$ сек $)$ & $90,6(85,5-94,0)$ & $89,7(84,7-89,7)$ & 0,031 \\
\hline $\mathrm{Va},(\mathrm{cm} / \mathrm{ceк})$ & $42,8(36,3-48,9)$ & $40,3(30,7-40,3)$ & 0,001 \\
\hline $\mathrm{Ve} / \mathrm{Va}$ & $2,1(1,9-2,3)$ & $2,5(2,5-2,8)$ & 0,001 \\
\hline DT, сек & $0,14(0,13-0,14)$ & $0,13(0,13-0,14)$ & 0,003 \\
\hline IVRT, сек & $0,14(0,11-0,14)$ & $0,12(0,08-0,12)$ & 0,001 \\
\hline IVCT, сек & $0,11(0,09-0,11)$ & $0,16(0,07-0,16)$ & 0,001 \\
\hline$\Phi \mathrm{B}, \%$ & $72,7(71,5-74,0)$ & $74,0(71,0-78,0)$ & 0,017 \\
\hline ФУ, \% & $40,7(40,7-40,9)$ & $42,0(41,0-42,0)$ & 0,001 \\
\hline СИ, л/мин/м² & $3,5(3,4-3,5)$ & $3,2(3,1-3,2)$ & 0,001 \\
\hline
\end{tabular}

Примечание: p - достоверность различия, КДР ПЖ - переднезадний конечный диастолический размер правого желудочка, Ао переднезадний конечный диастолический размер аорты, АК - размер раскрытия аортального клапана, ЛП - переднезадний конечный диастолический размер левого предсердия, ПП - правое предсердие, ТМЖПд - толщина межжелудочковой перегородки в диастолу, ТМЖПс - толщина межжелудочковой перегородки в систолу, ТЗСЛЖд - толщина задней стенки ЛЖ в диастолу, ТЗСЛЖс - толщина задней стенки ЛЖ в систолу, КДР ЛЖ - переднезадний конечный диастолический размер ЛЖ, КСР ЛЖ - переднезадний конечный систолический размер ЛЖ, Vmax ПК - максимальная скорость кровотока на уровне пульмонального клапана, Рgmax ПК - градиент давления крови при прохождении через пульмональный клапан, Vmax MK - максимальная скорость кровотока на уровне митрального клапана, Pgmax MK - градиент давления крови при прохождении через митральный клапан, Vmax АK - максимальная скорость кровотока на уровне аортального клапана, Pg max AK - градиент давления крови при прохождении через аортальный клапан, Vmax $\mathrm{TpK}$ - максимальная скорость кровотока на уровне трикуспидального клапана, Pg max TpK - градиент давления крови при прохождении через трикуспидальный клапан, Ve - максимальная скорость раннего пика Е трансмитрального кровотока, Vа - максимальная скорость позднего пика $\mathrm{A}, \mathrm{Ve} / \mathrm{Va}$ - отношение максимальных скоростей потока через митральный клапан, DT - время замедления потока раннего диастолического наполнения ЛЖ, IVRT - время изоволюметрического сокращения ЛЖ, IVCT - время изоволюметрического сокращения ЛЖ, ФВ - фракция выброса ЛЖ, ФУ ЛЖ - фракция систолодиастолического укорочения ЛЖ, СИ - сердечный индекс.

САД в тестовой группе было не симметричным (критерий H. Lilliefors, $\mathrm{p}<0,05)$, поэтому для сравнения групп использовался критерий Mann-Whitney U-test.

\section{Результаты и обсуждение}

Исследование показало, что симпатикотония и парасимпатикотония у молодых женщин с ИАГ ассоциируются с различными вариантами ремоделирования сердца (таблица 2).
Женщины с симпатикотонией (положительным ВИ) характеризовались достоверным уменьшением структурных параметров сердца: размеров всех камер и отверстия аорты; снижением сократительной функции (неэффективная систола): меньшими значениями толщины межжелудочковой перегородки в систолу, фракции укорочения, времени изоволюметрического сокращения левого желудочка (ЛЖ); замедлением релаксации ЛЖ: уве- 
личением времени изоволюметрического расслабления ЛЖ, которое отражает также повышение давления в аорте, времени замедления потока раннего наполнения. Наряду с этим наблюдалось ускорение внутрисердечной гемодинамики: увеличение скоростей кровотока и градиентов давления на митральном, трикуспидальном клапанах и клапане легочной артерии, скоростей раннего и позднего диастолического наполнения ЛЖ. Изменения в ранней диастоле ЛЖ ассоциированы с повышением давления в левом предсердии, что отражалось на параметрах максимальной скорости позднего пика А, времени изоволюметрического сокращения ЛЖ и времени замедления потока раннего диастолического наполнения ЛЖ. В целом в данной группе наблюдался гиперкинетический тип кровообращения (увеличение сердечного индекса).

Женщины с парасимпатикотонией (отрицательным ВИ) имели рестриктивный тип диастолической дисфункции: нарушение релаксации и повышение жесткости ЛЖ, увеличение соотношения Е/А.

Тонус кровеносных сосудов и уровень АД в организме регулируются слаженной работой многих систем и механизмов, среди которых важную роль играет эндотелий сосудов. Секреция оксида азота (NO) - одна из ключевых функций эндотелиальных клеток, изменяющаяся при различных заболеваниях [4]. Известно, что высвобождение из эндотелиальных клеток кровеносных и лимфатических сосудов, сердечных полостей эндотелиального релаксирующего фактора NO происходит при стимуляции M1, М2 и М3-холинорецепторов благодаря прямому воздействию ацетилхолина (АЦХ), который является основным нейромедиатором парасимпатического отдела АНС. Высвобождению АЦХ непосредственно в желудочки сердца способствует ишемия миокарда, вызывающая активацию внутрисердечных мускариновых рецепторов [5].

В настоящее время в качестве ведущего патогенетического механизма ИАГ у молодых людей рассматривается склонность к гипероксидазотемии [6]. С этой точки зрения логично было бы предположить, что ИАГ у пациентов обусловлена гипероксидазотемией вследствие высокой активности парасимпатического отдела АНС, эффектом главного ее медиатора - АЦХ. Однако роль АНС в формировании ИАГ более сложна и включает различные механизмы снижения АД, которые, возможно, задействованы и в ремоделировании миокарда.

Результаты представленного исследования показали, что подавляющее большинство обследованных женщин имеют признаки симпатической активности: положительный ВИ, более высокие значения ЧСС и диастолического АД, более низкую массу тела. Известно, что АЦХ обладает стимулирующим влиянием на периферические Н-холинорецепторы, тем самым активируя симпатическую активность (никотиноподобное действие) через возбуждение симпатических ганглиев, повышение выделения адреналина хромаффинными клетками мозгового вещества надпочечников [7]. В результате появляется тахикардия, сужение сосудов и, как следствие, повышение АД. Тем не менее, у симпатического отдела АНС (САНС), активированной гипероксидазотемией под влиянием АЦХ, отсутствуют достаточные резервы: ЧСС не достигает выраженности тахикардии, повышается изолированно диастолическое АД. Аналогичные результаты по уменьшению резервных возможностей САНС подтверждены и другими исследованиями [8]. Быстрое истощение САНС в условиях хронической гипотонии было показано у детей с первичной артериальной гипотензией при исследовании параметров сердечно-сосудистой системы во время активной клиноортостатической пробы [9]. В литературе также имеются сведения о том, что даже прием вазопресcopa Midodrine у женщин с гипотензией (среднее АД 96/61 мм рт.ст.) приводил к заметному снижению ЧСС [10]. Недостаточную реакцию САНС можно объяснить регулирующим влиянием NO: увеличение его концентрации ведет к усилению парасимпатического и торможению симпатического влияния на сократительную активность кардиомиоцитов [7]. Слабая активация САНС может быть также связана с АЦХ, который в малых концентрациях облегчает, а в больших - тормозит синоптическую передачу [7].

Теоретически симпатикотония не должна приводить к ИАГ. Но, как известно - пациенты с ИАГ неоднородны по состоянию баланса АНС, что было ранее подтверждено [11]. И среди пациентов с ИАГ есть пациенты как с парасимпатикотонией, так и симпатикотонией. Этого на первый взгляд, по стандартной логике не должно быть. Но факты свидетельствуют о другом. Поэтому было высказано предположение, что ИАГ состоит из двух групп, если их делить по активности отделов АНС. В одной группе в большей мере преобладает выраженная парасимпатическая активность с полным подавлением САНС. А в другой группе, на фоне не выраженной ПАНС, еще есть признаки существования САНС, которая была зафиксирована по положительному ВИ. Вероятно, это и есть сохранившаяся, еще не утраченная САНС, указывающая на ее слабую, но еще функционирующую у данной группы пациентов. В данном случае правильно думать об “относительной симпатикотонии”, чем об абсолютной.

Описанный патогенетический механизм вегетативной регуляции АД при ИАГ, характеризуется преобладающей ПАНС в сочетании со слабой адаптационной реакцией симпатоадреналового отдела АНС, который, как предполагают, может быть обусловленной высокой концентрацией АЦХ и NO. Выявленная симпатическая активность у женщин 
I группы, согласно критериям Кердо, является “относительно" недостаточной на фоне высокой активности парасимпатического отдела АНС (ПАНС). Следовательно, ВИ при ИАГ указывает не на превалирование симпатикотонии, а лишь на признаки ее активации. II группа наблюдаемых женщин с ИАГ не имела заметных признаков САНС, и гемодинамика у них находилась под преобладающим влиянием ПАНС.

Преобладанием активности того или иного отдела АНС можно объяснить и разницу в структурно-функциональных показателях сердца между женщинами изучаемых групп. Вероятно, основные медиаторы АНС вызывают разные варианты ремоделирования сердца при ИАГ. Ранее было доказано, что медиаторы САНС, адреналин и норадреналин в низких и высоких концентрациях способствуют отеку внеклеточного матрикса и фиброзу миокарда, особенно в условиях постоянной САНС [12], которая играет негативную роль в развитии и прогрессировании нарушений кардиальной гемодинамики [13]. Причем экспериментальным путем показано, что адреналин и норадреналин приводят к ремоделированию различных отделов сердца [14]. Вполне вероятно, что уменьшение размеров камер сердца и аорты, наличие признаков систолической дисфункции на фоне гиперкинетического типа сердечной гемодинамики в I группе женщин связаны с влиянием медиаторов САНС. Известно также, что АЦХ и NO, медиаторы ПАНС, оказывают кардиопротекторное влияние: снижают ЧСС, улучшают релаксацию миокарда [15]. Однако при ИАГ высокие концентрации АЦХ и NO (превышающие таковые у людей с нормальным АД) обладают повреждающим, токсическим действием на кардиомиоциты [16]. У обследованных женщин с преобладанием ПАНС отсутствовали признаки структурно-функциональной перестройки сердца, выявленные в I группе, однако наблюдалась диастолическая дисфункция, которая может быть кардиальным проявлением избытка NO.

Следует констатировать, что варианты ремоделирования сердца зависят от степени активности САНС, что, вероятно, связано с имеющимся патофизиологическим фоном ИАГ - гипероксидазотемией и высокой активностью АЦХ. Были выделены два типа ремоделирования сердца при ИАГ у молодых женщин, которые ассоциируются с преобладанием различных отделов АНС в регуляции АД:

- сочетание низкого АД с признаками слабой активности САНС (ВИ положительный) характеризуется признаками гипотрофии сердца и систолической дисфункцией;

- сочетание низкого АД без признаков симпатической активности АНС (ВИ отрицательный или равен 0) проявляется рестриктивным типом диастолической дисфункции.
Понимание механизмов поддержания АД в условиях хронический гипотензии, позволяет перейти к обсуждению вопроса о коррекции ИАГ. Как показали исследования [10], попытки искусственного стимулирования САНС могут привести к негативной реакции сердечно-сосудистой системы. Очевидно, верным путем нормализации АД у молодых женшин с ИАГ является "освобождение” САНС от избыточного “давления” блуждающего нерва за счет уменьшения концентрации АЦХ и NO. Такой эффект возможен за счет снижения ПАНС при использовании холинолитиков (парасимпатических агонистов) - атропина и его аналога тригексифенидила (используется в лечении болезни Паркинсона [17], или реактиваторов антихолинэстеразы, и их комбинации. В качестве альтернативы можно рассматривать и Н-холинолиномиметики, которые стимулируют Н-холинорецепторы как парасимпатических, так и симпатических ганглиев, и мозговое вещество надпочечников (Н-холинорецепторы хромаффинных клеток).

Предполагаем, что использование указанных препаратов у молодых женщин с ИАГ будет способствовать формированию сбалансированной и эффективной регуляции АНС за счет повышения симпатической активности, что приведет к нормализации параметров гемодинамики: повышению тонуса артерий и вен; улучшению инотропной и хронотропной функций сердца; кардиопротекторному эффекту за счет торможения гибели кардиомиоцитов, вызываемой различными видами стресса; регрессии ремоделирования сердца; а также нивелирует субъективную симптоматику [18].

\section{Заключение}

При ИАГ у 71\% молодых женщин преобладает САНС. Симпатикотония и парасимпатикотония при ИАГ ассоциируются с различными вариантами ремоделирования сердца.

Гипотрофия сердца (уменьшение полостей сердца и толщины стенок миокарда), снижение сократительной функции и нарушение релаксации ЛЖ у молодых женщин с ИАГ ассоциируются со слабой активацией САНС на фоне парасимпатикотонии.

Рестриктивный тип диастолической дисфункции у молодых женщин с ИАГ ассоциируется с парасимпатикотонией и отсутствием признаков активации САНС.

Перспективным направлением коррекции дисфункции АНС, регрессии ИАГ и ремоделирования сердца является использование холинолитиков и реактиваторов антихолинэстеразы.

Конфликт интересов: все авторы заявляют об отсутствии потенциального конфликта интересов, требующего раскрытия в данной статье. 


\section{Литература/References}

1. Baev VM, Koryukina IP, Kudryavtseva EN, et al. Cardiac hypotrophy in young women with low blood pressure. Biology and Medicine (Aligarh) 2014;6(1):1-6. http://www. biolmedonline.com/Articles/Vol6_1_2014/BM-005-14_Baev_et_al.pdf.

2. Baev VM, Agafonova TYu, Samsonova OA, et al. Isolated diastolic dysfunction as a result of hypernitricoxidemia in arterial hypotension. Cardiovascular Therapy and Prevention. 2017;5:16-9. (In Russ.) Баев В. М., Агафонова Т. Ю., Самсонова О. А и др. Изолированная диастолическая дисфункция как результат гипероксидазотемии при артериальной гипотензии. Кардиоваскулярная терапия и профилактика. 2017;5:16-9. doi:10.15829/1728-8800-2017-5-16-19.

3. Fajda OI, Hrinchenko BV, Snihur OV, et al. What Kerdoe's Vegetative Index reallyreflects? J Educat, Health and Sport. 2015;5(12):279-88. doi:10.5281/ zenodo.35421.

4. Zhao Y, Vanhoutte PM, Leung S. Vascular nitric oxide: Beyond eNOS. J Pharmacologl Scien. 2015;2(129):83-94. doi:10.1016/j.jphs.2015.09.002.

5. Pickard JM, Burke N, Davidson SM, et al. Intrinsic cardiac ganglia and acetylcholine are important in the mechanism of ischaemic preconditioning. Basic Res Cardiol. 2017;112(2):11. doi:10.1007/s00395-017-0601-x

6. Sikorski AV. The role of endothelial vasoactive factors in the development of arterial hypotension in children. Medicinskij zhurnal. 2013;3(45):102-6. (In Russ.) Сикорский А. В. Роль вазоактивных факторов эндотелия в развитии артериальной гипотензии у детей. Медицинский журнал. 2013;3(45):102-6. URL:https:// sgma.info/ru/issues-archive/2017.html?download=365:2017-01-18 (дата обращения: 4.05.2018).

7. Pocock G, Richards Ch, Richards D. Human physiology. Oxford: Oxford University Press 2013;p.848. ISBN 978-019-957493-3.

8. Grunberg $\mathrm{H}$. The Cardiovascular risk factor profile of Estonian school children. JACC. 1998;1(87):37-42. doi: 10.1111/j.1651-2227.1998.tb01382.x.

9. Ryvkin Al, Teplova Yu, Kuznetsova OV. Primary arterial hypotension in children Features of the clinic, general hemodynamics in children with arterial hypotension and signs of connective tissue dysplasia. LAP LAMBERT Academic Publishing. 2014 80 р. (In Russ.) Рывкин А.И., Теплова Ю. В., Кузнецова О. В. Первичная артериальная гипотензия у детей. Особенности клиники, общей гемодинамики у детей с артериальной гипотензией и признаками дисплазии соединительной ткани. LAP LAMBERT Academic Publishing. 2014. 80 c. ISBN-13: 978-3-659-54210-7.

10. Duschek S, Hoffmann A, Reyes Del Paso GA. Autonomic Cardiovascular Control and Executive Function in Chronic Hypotension. Ann Behav Med. 2017;3(51):442-5. doi:10.1007/s12160-016-9868-7.
11. Baev VM, Kudryavtseva EN. Adaptation to physical load and the state of the autonomic nervous system in young women with low blood pressure. Patologicheskaia fiziologiia i eksperimental'naia terapiia. 2015;4:97-100. (In Russ.) Баев В. М., Кудрявцева Е.Н. Адаптация к физической нагрузке и состояние вегетативной нервной системы у молодых женщин с низким артериальным давлением. Патологическая физиология и экспериментальная терапия. 2015;4:97-100. doi:10.25557/00312991.2015.04.97-100

12. Veber VR, Zhmailova SV, Rubanova MP, et al. Effect of epinephrine administration on myocardial remodeling in experimental study. Rational Pharmacotherapy in Cardiology. 2017;13(3):378-82. (In Russ.) Вебер В.Р., Жмайлова С. В., Рубанова М.П. и др. Ремоделирование миокарда под влиянием адреналина в эксперименте. Рациональная фармакотерапия в кардиологии. 2017;13(3):37882. doi: 10.20996/1819-6446-2017-13-3-378-382.

13. Kishi T. Heart failure as an autonomic nervous system dysfunction. J Cardiology. 2012; 2(59):117-22. doi: 10.1016/j.jjcc.2011.12.006.

14. Veber VR, Rubanova MP, Zhmailova SV, et al. Dopamine effect on cardiac remodeling in experiment. Rational Pharmacotherapy in Cardiology. 2009;5(1):73-6. (In Russ.) Вебер В.Р., Рубанова М. П., Жмайлова С. В. и др. Влияние дофамина на ремоделирование левого и правого желудочков сердца в эксперименте. Рациональная фармакотерапия в кардиологии. 2009;5(1):73-6. doi:10.20996/1819-6446-20095-1-73-76.

15. Bonnefont-Rousselot D, Mahmoudi A, Mougenot N, et al. Catecholamine effects on cardiac remodelling, oxidative stress and fibrosis in experimental heart failure. Redox Rep 2002;7(3):145-51. doi:10.1179/135100002125000389.

16. Abramochkin DV, Borodinova AA, Nikolsky EE, et al. Nitric oxide modulates intensity of non-quantal acetylcholine release in myocardium of the right atrium of rat. Biochemistry (Moscow) Supplement Series A: Membrane and Cell Biology. 2012;6(4):288-93. doi:10.1134/S1990747812040022.

17. Hauser RA, Lyons KE, McClain TA, et al. Parkinson Disease Treatment \& Management. URL: http://emedicine.medscape.com/article/1831191-treatment\#d8 (дата обращения: 7.05.2018)

18. O'Connell TD, Jensen BC, Baker AJ, et al. Cardiac Alpha1-Adrenergic Receptors: Novel Aspects of Expression, Signaling Mechanisms, Physiologic Function, and Clinical Importance. Pharmacol Rev. 2014;1(66):308-33. doi:10.1124/pr.112.007203. 